optimum temperature for the breeding of Calandra is about $82^{\circ} \mathrm{F}$., but somewhat higher for Rhizopertha. C. oryzae may increase $700-f o l d$ in sixteen weeks, which makes it a more dangerous pest than granaria, which has a slower rate of multiplication. On the other hand, adults of the latter species were found to survive the winter in this country at ordinary room temperature, whereas nearly all those of oryzae were killed off. Rhizopertha succumbs after three minutes' exposure at about $146^{\circ} \mathrm{F}$., while $120^{\circ}-130^{\circ} \mathrm{F}$. is the lethal temperature for both species of Calandra.

As the consequence of information accumulated in the laboratory, tests along commercial lines need to be carried out in order to ascertain the practicability or otherwise of the knowledge thus obtained. We strongly urge that large-scale tests should be inaugurated with as little delay as possible. If such tests confirm the conclusion that the most satisfactory method for the storage of grain in bulk, over lengthy periods, is in airtight silos or granaries, the Grain Pests Committee is to be congratulated upon a notable achievement. The construction of such receptacles would involve a high initial cost, but probably not excessive when the annual loss from weeviling is recounted. As the authors point out, by such a method of storage we should be provided with a means of maintaining a reserve of cereals in the event of war or crop failure, and, we may add, of economic or financial difficulties.

\title{
Some Applications of Physics to War Problems.
}

$[\mathrm{N}$ an address to the Physics Section of the 1 American Association for the Advancement of Science, delivered at the St. Louis meeting in December last and published in Science for March 5, Prof. Gordon F. Hull describes the work done by a number of American mathematicians and physicists in elucidating the various problems that arose during the war in connection with longrange and anti-aircraft gunnery. It may be of interest, therefore, to record the efforts of a number of British men of science, made at a much earlier date during the war, on which (and on the work of the French) the developments of American scientific gunnery as described by Prof. Hull were largely based.

Up to the spring of 1916 the developments of British ballistic science had come largely through the Ordnance Committee at Woolwich, which during the war was fortunate in having an officer of considerable mathematical attainments as head of the ballistic office. The mass of work, however, and the extraordinary variety and difficulty of the problems that arose, especially in connection with the new science of anti-aircraft gunnery, made it necessary for the Ordnance Committee to seek help from outside; and from 1916 onwards the investigation of problems in " external ballistics" devolved largely on the Anti-aircraft Experimental Section of the Munitions Inventions Department. The A.A.E.S., as it was called, consisted of a number of mathematicians and other men of science, mainly fellows and scholars of Cambridge colleges, some from the Patent Office, one from Oxford, and three fellows of the Royal Societysome in military, some in naval, and some in civilian clothes.

The work of this group was undertaken at H.M.S. Excellent, Port'smouth, at Rochford Aerodrome, at the National Physical Laboratory, at University College, London, and at a variety of other places. It consisted largely of trials with anti-aircraft guns, shells, and fuses, recording the No. 2634 , VOL. IO5] positions of shell-bursts at heights up to $33,000 \mathrm{ft}$., observing and calculating the effects of winds and of pressure and temperature abnormalities, developing the mathematical theory of ballistic calculations, and investigating the behaviour or the causes of failure and irregularity of fuses. In addition to this, work of considerable mathematical and physical interest was done, some of which will be published, on the general dynamics of shell flight (such problems as the stability of shells, the effects of rotation of the earth, "drift," the "twisted trajectory of the shot," etc.), and on the pressure distribution on the head of a shell in flight. The solution of some of these problems, undertaken originally in connection with anti-aircraft gunnery, had, in the end, a considerable bearing upon the theory of gunnery in 'general.

The A.A.E.S., in addition to its main work in investigating the problems of gunnery, did a large amount of routine computing of range tables in conjunction with the staff of the Galton Laboratory, and performed a number of interesting and important trials on time-fuses in co-operation with the Engineering Department of University College, London. It carried out far-reaching experiments on the use of sound-locators for the detection of aircraft, and in conjunction with the R.E. and the Air Force on the co-operation between such soundlocators and searchlights; the military equipment and methods finally adopted were based directly on these experiments. It tested both the theory and the use of a number of instruments required for anti-aircraft work, such, for example, as rangefinders, height-finders, and "predictors" (instruments for predicting the "future position" of the target at the moment the shell bursts); and finally it had what was known familiarly as a "travelling circus," which moved about in Great Britaln and France recording the results of practice anti-aircraft shoots, and investigating the performance of guns and instruments. 
The work terminated in April, 1919, and an interesting body of scientific workers was disembodied, disbanded, or demobilised. The more important practical results of their work are being recorded for the use of the military authorities: the methods adopted, however, and many of the observations, calculations, and speculations, the personalities of the men themselves, their various homes and adventures, the help (and the hindrance) they received from various people and officials, would provide material for a fascinating history of some "applications of physics to war problems" -a history, however, which will probably rever be written.

\section{Obituary.}

\section{Prof. J. A. McClelland, F.R.S.}

$\int \mathrm{O}$ HN ALEXANDER MCCLELLAND was born at Coleraine in I87o. Leaving the High School, he studied in University (then Queen's) College, Galway, and after a distinguished course he obtained a junior fellowship of the Royal University. Proceeding to Trinity College, Cambridge, he worked under Sir J. J. Thomson, and was one of the brilliant band of investigators who made history in those days in the Cavendish Laboratory, being contemporary with Sir Ernest Rutherford, Prof. Townsend, and others. In succession to the late Prof. Preston he became professor of experimental physics in University College, Dublin, and quickly began his famous researches on secondary radio-activity.

Shortly after becoming a fellow of the Royal Society, the National University was founded, and McClelland was appointed a member of the senate and of the governing body of University College, Dublin, positions which he held until his death. $\mathrm{He}$ at once devoted himself to the planning of the physical laboratory of the college. His efforts were highly successful, and a very efficient research department quickly sprang up, which accomplished wonders, considering the resources at its disposal. The number of students in the college in the beginning was 550 , and at the present moment it is $135^{\circ}$, and the task of keeping pace with such rapid growth might easily have absorbed all the time of a lesser man; but McClelland had many other spheres of activitysecretary to the Royal Irish Academy, member of the Board of National Education, member of the council of the Royal Dublin Society, and governor of St. Andrew's College--yet he undertook a still more onerous task. He became a member of the Privy Council Committee on Scientific and Industrial Research, which necessitated frequent journeys from Dublin to London, and this during the war, when, apart from the great discomforts of travelling in those times, every crossing of the Irish Sea was a gamble with death. The constant strain was too much for him, and oftentimes his friends urged him to take a long rest. His sense of duty, however, prevented him from paying attention to his bodily weakness, and when at last the college authorities persuaded him to take a six months' rest, it was too late.

As a man of science the outlook of McClelland and his method of exposition had all the clarity of Faraday. Although, unlike Faraday, he had a sound mathematical training, his mind worked in the direction of a "common-sense " explanation of the most complicated phenomena. This made him especially valuable as a teacher, whether for advanced or elementary work. It has been the privilege of the writer to sit with him on many boards, and this same faculty of cutting away the unessentials of a question, and presenting it in its reality, rendered him a valued colleague in many matters far removed from the world of science. A Presbyterian in religion, he was followed to his grave by men of every shade of thought. It is a commonplace almost devoid of meaning to speak of a loss as irreparable, but in his college and in the wider public life of Ireland everyone who knew him feels that a man has gone from amongst us whose place it will be impossible to fill.

A. W. C.

\section{Dr. J. G. Bar'tholomew.}

Geographers throughout the world will recognise that scientific geography has sustained a grave loss through the death suddenly at Cintra about midnight on April I3 of Dr. Bartholomew, the head of the cartographical firm which has been known since 1889 as the Edinburgh Geographical Institute.

Dr. Bartholomew was a native of Edinburgh, where he was born on March 22, 1860, and where he was educated at the High School and the University. As a young man he entered the business founded by his grandfather. From the age of twenty-two he took an active part in its management, and at twenty-nine he succeeded his father in the supreme control. By this time he had devised the method of representing topographical features by the system known as layering, which has made the Edinburgh Geographical Institute celebrated throughout the world, and is now copied in all other cartographical establishments. Like many other novel ideas, it may seem very obvious once it has been introduced. It merely consists in the spreading of distinctive colours, tints, or shades between successive contours on a contoured map. It accordingly gives no information as to the physical features additional to that furnished by the contours; but it

NO. 2634 , VOL. IO57 